\title{
How to Meet Legitimate Expectations of Patients when Authorized Medicinal Products are not Available
}

\section{Paola Minghetti* and Francesca Selmin}

Department of Pharmaceutical Sciences - University of Milan - via G. Colombo, 71 - 20133, Milan, Italy

It is well-known that quality, efficacy and safety have to be guaranteed for medicinal products, but the point is at which level these attributes have to be satisfied. Generally speaking, based on scientific expertise and progress of a specific period of time the regulatory framework defines the minimal level that has to be documented before reaching the market. A further question is if this level should be the same for all types of drugs considering that if no authorized drugs are available for a clinical indication or in a subpopulation, how a physician can safeguard patient's right and health? Indeed, in an ideal world, all patients should be treated by drugs for which the maximum levels of efficacy, safety and quality have been granted after the evaluation of specific experimental data. Nevertheless, authorized medicinal products placed on the market do not cover all therapeutic needs; for instance, drugs for rare pathologies as well as suitable dosage forms or doses for paediatric population are not available. In the case of orphan medicines, the major obstacle to obtain market authorization is to prove their efficacy and safety since the conventional design used in clinical trials makes it difficult for this to be fully accomplished: there are too few patients, often geographically dispersed, and most of the time there is no other treatment available than the medicine under evaluation. This situation is even more complex when medicines are intended for the paediatric population, where ethical concerns have other implications [1-4]. Indeed, as many as half of all paediatric drug prescriptions were for either unlicensed medications or off-label use of licensed medications and $67 \%$ of paediatric patients received an unlicensed or off-label [5].

To meet the legitimate patients' right to receive treatment, the physician can prescribe pharmacological treatments other than for which the marketed authorization has been granted in the following scenarios: off-label prescriptions; compounded medicinal products; compassion use of medicinal products; prescription of medicinal products authorized in foreign countries [6].

The efficacy of all such therapeutic alternatives has not been proved according to the requirements established by the regulatory framework and the physician has to choose the active pharmaceutical ingredient on the basis of good sound scientific reasoning. The most suitable medicinal products will be selected while considering availability, costs and local regulatory requirements. If none of these alternatives are pursued, the physician shall initiate a clinical trial which assure safety to a high level and that protocols are carried out within ethical guidelines.

To avoid misuses of unlicensed drugs, the Authorities have to regulate their use. Probably a case-by-case approach is essential in order to establish the minimum requirements to fulfil. Indeed, in the case of the off-label use of drugs with market authorization, the quality is not under discussion, while the risk/benefit assessment is duty bound to physicians or regulatory framework. For example, in Italy at least a clinical study of Phase II as to be concluded.

The compassionate use normally is well regulated in all Countries. Extemporaneous preparations require attention to the quality other than risk/benefit aspects. Indeed, GMPs are not fully applicable in compounding pharmacies and adapted guidelines are elaborated (e.g. PIC [7]) or under discussion.

Considering these issues, can we pose limitations to the use of these products? Can we make a positive list? Probably not, above all is the light of the multiplicity of situations and the continuous progress of science.

The Public Administration must safeguard patients' right and health, evaluating the appropriateness of medical prescriptions. The physician is the one who has the knowledge and the tools to properly diagnose a pathology and, therefore, to select the most appropriate therapy. Obviously, to completely legitimate the patient's right to be treated it would be highly desirable to increase the number of granted marketing authorizations or to stimulate clinical studies. Even if the legislator defined a specific set of rules, there will be inevitably the need to fill the gaps with unlicensed drugs.

The more rigid the rules, the higher the risk of not legitimating the patient's right to be treated because a suitable medical product will not be available or cannot be prescribed.

The Public Administration should not limit a physician's freedom to prescribe only on-label approved drugs in an attempt to avoid misuse. The physician and the pharmacist have to be trained to assess the risk associated with all concerns to treatment or not a patient with an unlicensed drug. The Committee of Ministers of the Council of Europe enabled recently a resolution for extemporary preparations [8].

To favour the physicians' best practice and to support their choices, high-value information should be easily available. The Public Administration and agencies should develop a programme to ensure availability of data and public access to databases, after defining adhoc levels of safety and efficacy. To facilitate the work and to avoid duplication of studies, investigators and centres with specific expertise should be linked together in research networks. An effort should be made to include as many results as possible of clinical trials carried out in non-profit-making institutions.

On the basis of high-value evidence national and/or international scientific committees should also establish a decisional tree to support physicians' decision in prescribing drugs of any origins and to guide national health systems and health insurance schemes in the selection of reimbursable therapy or treatments.

Corresponding author: Paola Minghetti, Department of Pharmaceutical Sciences - University of Milan, via G. Colombo, 71 - 20133 Milan, Italy, Tel: +39-0250324535; Fax: +39-02503-24557; Email: paola.minghetti@unimi.it

Received May 28, 2012; Accepted May 28, 2012; Published May 30, 2012

Citation: Minghetti P, Selmin F (2012) How to Meet Legitimate Expectations of Patients when Authorized Medicinal Products are not Available. Pharmaceut Reg Affairs 1:e108. doi:10.4172/2167-7689.1000e108

Copyright: (c) 2012 Minghetti P, et al. This is an open-access article distributed under the terms of the Creative Commons Attribution License, which permits unrestricted use, distribution, and reproduction in any medium, provided the original author and source are credited. 
Citation: Minghetti P, Selmin F (2012) How to Meet Legitimate Expectations of Patients when Authorized Medicinal Products are not Available. Pharmaceut Reg Affairs 1:e108. doi:10.4172/2167-7689.1000e108

\section{References}

1. Woodfield $T$ (1999) Children and research: ethical and philosophical principles. Paediatr Nurs 11: 36-39.

2. Lamprill J (2002) Asking for children's assent to take part in clinical research. Good Clin Pract J 9: 9-12.

3. Cuzzolin L, Zaccaron A, Fanos V (2003) Unlicensed and off-label uses of drugs in paediatrics: a review of the literature. Fundam Clin Pharmacol 17: 125-131.

4. European Medicines Agency (2001) ICH Topic E11 Notes for guidance on the clinical investigation of medicinal products in the paediatric population. CPMP/ $\mathrm{ICH} / 2711 / 99$. European Medicines Agency, London.

5. Neubert A, Wong IC, Bonifazi A, Catapano M, Felisi M, et al. (2008) Defining off-label and unlicensed use of medicines for children: results of a Delph survey. Pharmacol Res 58: 316-322.

6. Minghetti P, Palmieri I, Selmin F (2010) When authorized medicinal products are not available: possible alternatives to meet legitimate expectations of patients. J Pharm Health Serv Res 1: 107-112.

7. Good preparation practices (PIC/S GPP): "Guide to good practices for the preparation of medicinal products in health care establishments", in Pharmaceutical Inspection Convention Pharmaceutical Inspection (PIC/S) Guide PE 010.

8. Resolution CM/ResAP (2011)1 on quality and safety assurance requirements for medicinal products prepared in pharmacies for the special needs of patients. Adopted by the Committee of Ministers on 19 January 2011at the 1103rd meeting of the Ministers' Deputies.
Submit your next manuscript and get advantages of OMICS Group submissions

Unique features:

- User friendly/feasible website-translation of your paper to 50 world's leading languages Audio Version of published paper

Digital articles to share and explore

Special features:

200 Open Access Journal

15,000 editorial team

- 21 days rapid review process

- Quality and quick editorial, review and publication processing

- Indexing at PubMed (partial), Scopus, DOAJ, EBSCO, Index Copernicus and Google Scholar etc

- Sharing Option: Social Networking Enabled

- Authors, Reviewers and Editors rewarded with online Scientific Credits

Better discount for your subsequent articles

Submit your manuscript at: http://www.omicsonline.org/submission/ 